04

\title{
Капельная эрозия катода в сильноточной вакуумной дуге
}

\author{
(C) К.К. Забелло ${ }^{1}$, А.А. Логачёв ${ }^{1}$, И.Н. Полуянова ${ }^{2}$, С.М. Школьник ${ }^{1}$ \\ ${ }^{1}$ Физико-технический институт им. А.Ф. Иофрфе РАН, Санкт-Петербург, Россия \\ ${ }^{2}$ Конструкторское бюро коммутационной аппаратуры, Севастополь, Россия \\ E-mail: zabellok@mail.ioffe.ru
}

Поступило в Редакцию 21 января 2019г.

В окончательной редакции 21 января 2019г.

Принято к публикации 28 января 2019г.

Показано, что в сильноточных вакуумных дугах, в которых имеет место оплавление части поверхности катода, в капельной эрозии есть вторая компонента. Помимо хорошо изученных капель, образующихся непосредственно в катодном пятне (которые можно назвать каплями первого рода), жидкая часть поверхности эмитирует капли (которые можно назвать каплями второго рода), существенно отличающиеся по размерам и скоростям. Механизм образования капель первого и второго рода различен.

DOI: 10.21883/PJTF.2019.08.47616.17708

Привязка вакуумной дуги к интегрально холодному катоду (охлаждаемый катод или импульсное питание дуги при токах десятки и сотни ампер) состоит из нестационарных (время жизни $\sim 10^{-5}$ s) микропривязок (радиус $\left.\sim 10^{-4} \mathrm{~cm}\right)-$ катодных пятен (КП). КП генерируют потоки ионов, нейтральных атомов и микрочастиц - капель. Исследования механизма генерации капель и их параметров (размеры, скорость, углы разлета) ведутся многие десятки лет. В настоящее время показано, что капли образуются в процессе формирования кратера КП [1,2]. Капли, генерируемые КП, меняются по размерам в широких пределах от долей микрометра до десятков микрометров [3]. Обнаружены капли наноразмеров [4]. Количество капель экспоненциально возрастает с уменьшением их диаметра, однако основные потери массы в капельной фазе происходят за счет капель размером $\sim 10 \mu \mathrm{m}$. Скорости капель по результатам различных измерений меняются также в широком диапазоне $10^{2}-10^{3} \mathrm{~m} / \mathrm{s}$ в зависимости от материала катода и размеров капель. Для меди среднее квадратичное значение скорости (rms) лежит в пределах 250-450 m/s, а для молибдена - в пределах 400-700 m/s [3]. Однако данные по скоростям капель противоречивы. Согласно данным [5], для меди скорости капель размером $1-10 \mu \mathrm{m}$ лежат в пределах $60-100 \mathrm{~m} / \mathrm{s}$.

В сильноточных разрядах даже при импульсном питании возможен разогрев значительной части поверхности катода в процессе горения дуги до высоких температур, a также ее оплавление. Это может изменить характер эрозионных процессов на катоде. Задачей настоящей работы является исследование состояния поверхности катода и эрозионных процессов на нем в сильноточных разрядах.

Нами выполнены эксперименты с сильноточными дугами (ток $I \leqslant 50 \mathrm{kA}$ ), горевшими в контактных системaх (КС), генерирующих аксиальное магнитное поле, с контактами из композиции $\mathrm{CuCr} 30$ диаметром $50 \mathrm{~mm}$. Дуга горела в вакуумной камере при постоянной откачке $\left(p \sim 10^{-4} \mathrm{~Pa}\right)$ и питалась полусинусоидальным током частотой $50 \mathrm{~Hz}$. Поджиг дуги осуществлялся размыканием контактов. Размыкание происходило не более чем через $1 \mathrm{~ms}$ после включения тока (длительность горения дуги $\geqslant 9 \mathrm{~ms}$ ). Привод обеспечивал скорость движения подвижного электрода $\sim 1 \mathrm{~m} / \mathrm{s}$. В экспериментах фиксировались осциллограммы напряжения и тока дуги. С помощью высокоскоростной видеокамеры Phantom MIRO M310, оснащенной объективом Carl Zeiss 100/2, осуществлялась видеосъемка поверхности катода. Съемка велась через боковой фланец вакуумной камеры под углом $\sim 8^{\circ}$ к поверхности катода в масштабе, при котором вся поверхность катода попадала в кадр. В этом случае по горизонтали одному пикселу соответствует $\sim 70 \mu \mathrm{m}$ на электроде. Часть сьемок была выполнена в большем масштабе (1 px соответствует $25 \mu \mathrm{m})$. Для анализа состояния катода в процессе горения дуги съемка велась через плотные серые фильтры с малыми экспозициями $\sim 10 \mu \mathrm{s}$. Это необходимо, чтобы избежать пересвета кадров излучением дуговой плазмы. Кроме того, проводилась съемка поверхности катода через интерференционный фильтр $(\lambda=775 \mathrm{~nm})$ с экспозицией $\sim 50-100 \mu \mathrm{s}$. Результаты этой съемки с помощью разработанной нами ранее методики [6] могут быть использованы для определения температуры катода в нуле тока, а также для оценки параметров капель (см. пояснения далее).

Анализ результатов сьемки через плотные нейтральные фильтры показал, что катодная привязка через 3-4 ms после поджига дуги охватывает всю рабочую поверхность катода и распределена по ней примерно однородно. Однако на спаде тока примерно за $1.5 \mathrm{~ms}$ до нуля тока структура привязки меняется. При умеренных токах $\left(I / I_{L}<0.7\right.$, где $I_{L}-$ максимальный ток, отключаемый такими КС) катодная привязка приобретает форму кольца, внешний диаметр которого совпадает с диаметром плоской части контакта, а внутренний растет по мере уменьшения тока. Вблизи нуля тока 
на периферии катода образуется узкое кольцо КП. Это объясняется тем, что на спаде тока аксиальное магнитное поле, генерируемое КС, в приосевой области уменьшается медленнее, чем на периферии контакта [7]. При $I / I_{L}>0.7$ приосевая область катода начинает плавиться. Это следует из того, что форма поверхности вблизи оси меняется. На ней вырастают бугры размером $\gtrsim 1 \mathrm{~mm}$, форма которых меняется: они вырастают, а затем разглаживаются. Примерно за $2 \mathrm{~ms}$ до нуля тока расплав застывает: движение расплава и изменение его формы прекращается. При $I / I_{L} \sim 0.8-0.9$ расплав на катоде образуется раньше, а затвердение происходит позже, незадолго до нуля тока. При этих токах катодная привязка незадолго до нуля тока уже не является чисто кольцевой. Внутри кольца вблизи оси катода на расплаве горят КП. При затвердевании поверхности КП погасают. Можно предположить, что КП существуют в приосевой области при уменьшении тока лишь в том случае, когда температура поверхности превосходит температуру плавления меди. При $I / I_{L} \sim 0.9-1$ поверхность катода затвердевает после нуля тока, и поэтому КП в приосевой области погасают только при занулении тока.

Горящие на расплаве КП могут привязываться к вершинам бугров, но большинство КП блуждает по боковой поверхности бугров и их подножию. В некоторых случаях КП перегревают отдельные бугры. Перегретые бугры начинают ярко светиться. Как было указано выше, бугры постоянно меняют свою форму. Особенно интенсивно меняют форму перегретые бугры. Возможно, потому, что у них из-за перегрева ниже вязкость. При этом от них могут отрываться фрагменты и капли. Фрагменты сразу начинают делиться на капли. Происходит нечто, напоминающее взрыв бугра. В результате КП, горящие на жидкой поверхности, вызывают интенсивную эмиссию капель. Пример описанных процессов приведен на рис. 1. КП, горевшие на буграх и вблизи них, перегрели бугры. Они „взорвались“, и в сторону анода веером разлетелись капли. Отметим, что эти капли генерируются не непосредственно КП. Эмиссия капель является результатом „взрыва“ бугров, перегретых КП. Поэтому мы называем их каплями второго рода, чтобы отличить от капель первого рода, генерируемых непосредственно КП, горящими на интегрально холодной твердой поверхности. Как видно, механизмы генерации капель первого и второго рода различны. Далее показано, что различны и их размеры и скорости.

Методика определения температуры поверхности электрода требует, чтобы съемки велись через интерференционный фильтр. Определение температуры возможно только после зануления тока. Перед нулем тока засветка от дуговой плазмы не позволяет определить температуру. Полученные результаты подтвердили, что при токах $I / I_{L} \sim 0.9-1$ температура поверхности катода в приосевой области в нуле тока выше температуры плавления меди. Подробно результаты этих измерений описаны в [8]. В настоящей работе мы используем
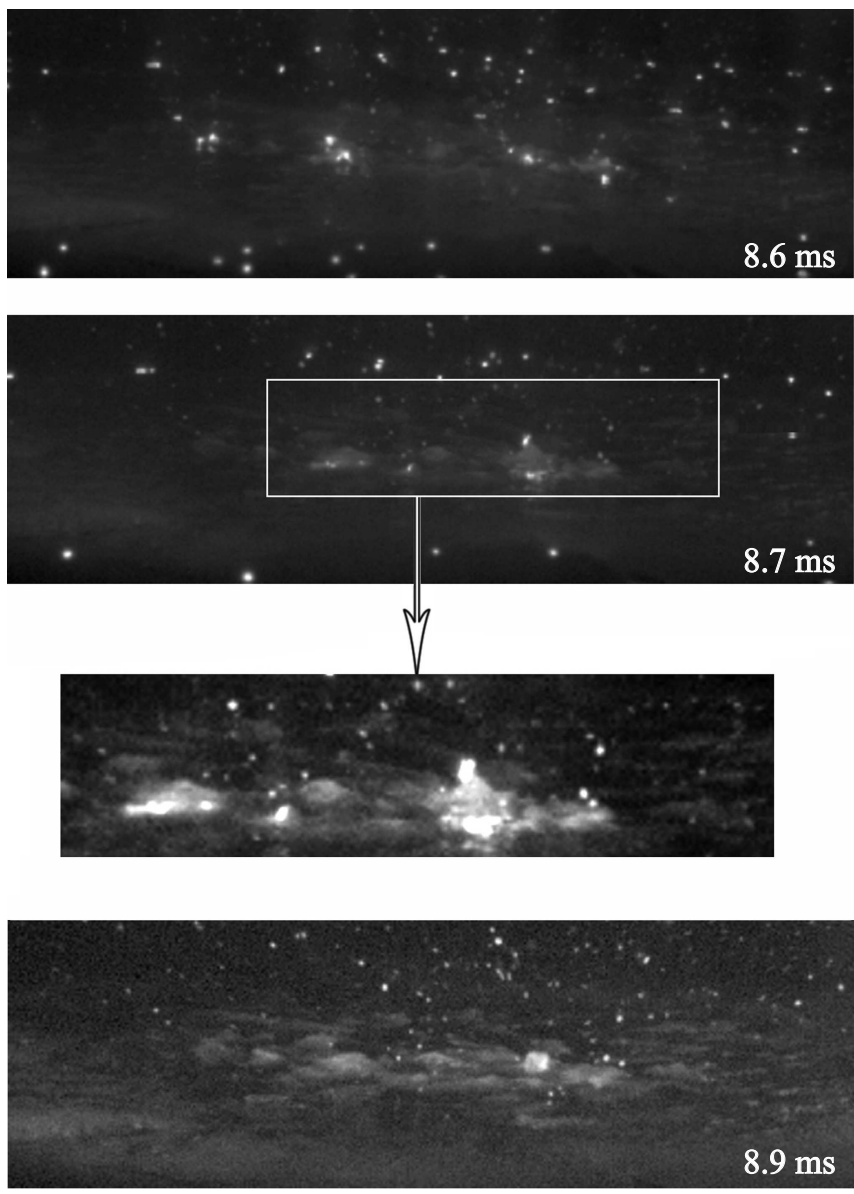

Рис. 1. Выборка кадров из видеосъемки катода при $I / I_{L} \sim 1$. Масштаб: $1 \mathrm{px}-70 \mu \mathrm{m}$ на поверхности катода. На кадрах указано время, прошедшее после поджига дуги.

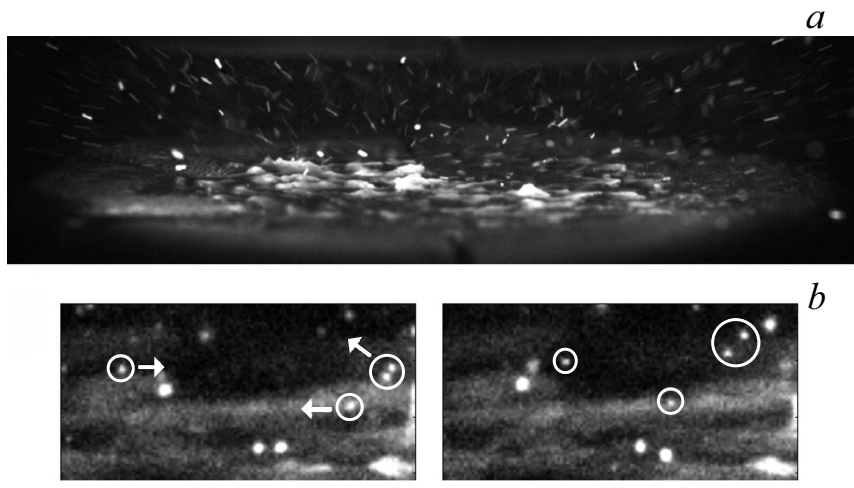

Рис. 2. Поверхность катода около нуля тока. $a-$ масштаб: $1 \mathrm{px}-70 \mu \mathrm{m}$ на поверхности катода, экспозиция $100 \mu \mathrm{s} ; b-$ масштаб: $1 \mathrm{px}-25 \mu \mathrm{m}$ на поверхности катода, экспозиция $7 \mu \mathrm{s}$, время между кадрами $50 \mu \mathrm{s}$.

результаты этих съемок для другой цели - для анализа капель, эмитированных катодом. Капли, эмитированные катодом, видны после погасания дуги и на съемках через плотные серые фильтры, однако из-за сильного подавления излучения фильтрами и коротких времен 
экспозиции различается небольшое количество наиболее ярких капель (отметим, что во время горения дуги капли вообще не видны, так как их яркость намного меньше, чем у КП). Значительно больше капель удается увидеть в нуле тока при съемках через интерференционный фильтр, которые проводились с большими экспозициями $\sim 50-100 \mu \mathrm{s}$. Это, по-видимому, капли второго рода, которые, как видно из дальнейшего рассмотрения, движутся относительно медленно. Капли первого рода движутся столь быстро, что за несколько микросекунд покидают разрядный промежуток, и мы не можем их увидеть на кадрах видеосъемки. На рис. 2, a приведен пример кадра, полученного в нуле тока. Амплитудное значение тока $I / I_{L} \approx 1.03$. При таком токе, как следует из изложенного выше, поверхность катода затвердевает после нуля тока. Поэтому вплоть до нуля тока на расплаве горят КП и соответственно происходят взрывы бугров, сопровождаемые генерацией капель. Видно, что разлет капель хаотичен по направлениям. Есть капли, летящие в плоскости, перпендикулярной направлению съемки. Такие капли оставляют вытянутые треки, так как экспозиция кадра большая. Измеряя длину трека, можно сделать оценку скорости капли. Размер капель в таких съемках определить не удается. Поэтому мы провели фотографирование в большем масштабе (на 1 рх приходится $25 \mu \mathrm{m})$ с маленькой экспозицией $(7 \mu \mathrm{s})$. Фотографировалась лишь часть электрода (приосевая). В этих съемках изображение капли получается примерно круглым и составляет 2-3 рх и более, т.е. размер капли может быть определен. Капель размером 1-2 pх достоверно обнаружить нам не удалось. Имеющиеся на рис. 2, $a$ маленькие яркие точки, по-видимому, отражают уровень шума. Увидеть их направленное движение не удавалось (однако вполне возможно, что среди них есть и капли малого размера). Эти съемки можно использовать для более точного определения скорости капель, если отобрать для анализа капли, летящие примерно поперек луча зрения, и проследить их положения от кадра к кадру. На рис. 2, $b$ в качестве примера показаны два отстоящих друг от друга на $\sim 50 \mu$ s кадра. Капли, движущиеся поперек луча зрения, отмечены кружками. Стрелки показывают направление их движения. Результаты анализа нескольких подобных съемок позволили составить гистограмму размеров капель и получить значения их скоростей, которые указаны над соответствующими столбиками гистограммы (рис. 3). Как видно из рисунка, основная часть капель имеет размер 50-75 $\mu$ m и летит со скоростью $\sim 10 \mathrm{~m} / \mathrm{s}$. Капли бо́льшего размера (150-175 $\mu \mathrm{m})$ обладают меньшими скоростями $(3-4 \mathrm{~m} / \mathrm{s})$. Отметим, что большое различие в размерах капель первого и второго рода не позволяет увидеть капли первого рода на кадрах видеосъемки (рис. 1), пространственное разрешение в наших экспериментах для этого недостаточно.

Генерация капель на расплавленном катоде сильноточного разряда ранее обсуждалась в работах $[9,10]$. В [9] при токах, вызывающих плавление катода, в

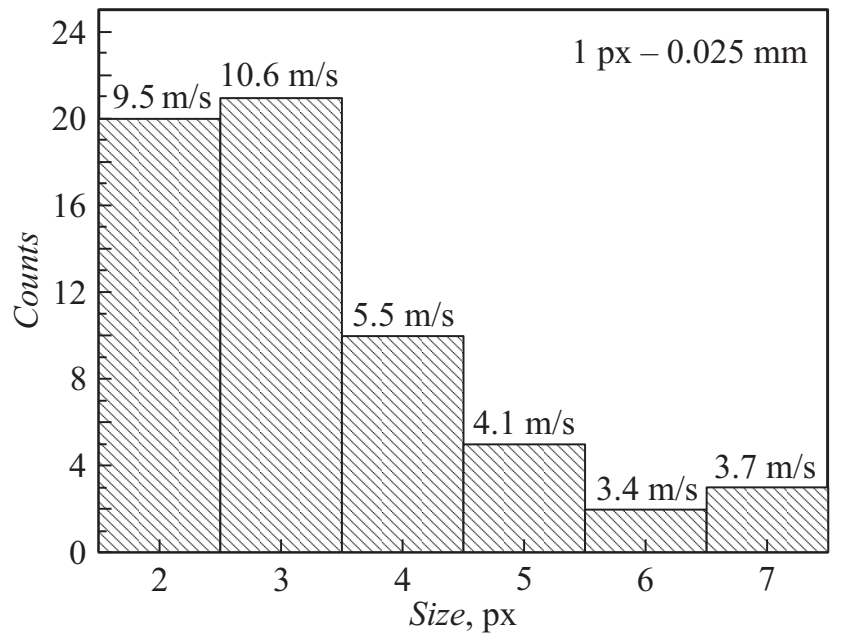

Рис. 3. Гистограмма размеров капель второго рода. Над каждым столбиком гистограммы указана скорость капель данного размера.

дуговом промежутке были обнаружены капли размером от 30 до $200 \mu \mathrm{m}$, летевшие со стороны катода со скоростями $1-10 \mathrm{~m} / \mathrm{s}$. Капли отрывались при волнообразных деформациях жидкой поверхности катода. Позднее в [10] был предложен другой механизм образования капель. Предполагалось, что на жидком катоде образуются выступы, на концах которых горят КП. Протекание тока вызывает вытягивание выступа и отрыв от него капли, которая летит по нормали к катоду. Скорость капли определяется скоростью роста выступа, которая оценена как $5 \mathrm{~m} / \mathrm{s}$. Размеры капель не были оценены. Экспериментальные результаты настоящей работы не противоречат тем, что получены в работе [9], однако находятся в противоречии с моделью генерации капель, предложенной в [10]. По нашим наблюдениям при взрыве бугров одновременно образуется много капель, которые веером разлетаются в разные стороны (рис. 1). Отметим, что авторы обеих работ пользуются термином „катодные капли“, который, конечно, отражает суть явления (капли отрываются от поверхности катода), но не учитывают того, что этот термин многие годы задолго до того, как были исследованы процессы на катодах в сильноточных режимах, использовался для обозначения капель, генерируемых катодным пятном на холодной твердой поверхности. Многие обзоры и монографии, например [3], содержат сведения именно о таких катодных каплях. Это может затруднять понимание и запутывать не слишком опытного читателя.

Таким образом, полученные в работе результаты показывают, что в сильноточных вакуумных дугах, в процессе горения которых часть поверхности катода оплавляется, характер капельной эрозии катода меняется. В эрозии появляется еще одна компонента. В первую очередь капли генерируются непосредственно КП, горящими на оставшейся твердой части поверхности катода. Это „обычные“, ранее описанные и изученные 
катодные капли [3], которые предлагается называть каплями первого рода. Но, кроме того, как следует из результатов наших исследований, капли генерируются на расплавленной части поверхности при „взрывах“ образующихся на жидкости бугров, разогреваемых КП. Эти капли предлагается называть каплями второго рода. Параметры (размеры и скорости) капель второго рода оценены в настоящей работе. Они существенно отличаются от параметров капель первого рода. Особенно сильно отличаются скорости (более чем на порядок величины). Параметры капель второго рода требуют дальнейшего изучения.

\section{Список литературы}

[1] Гашков М.А., Зубарев Н.М., Зубарева О.В., Месяи Г.А, Уйманов И.В. // ЖЭТФ. 2016. Т. 149. В. 4. С. 896-908.

[2] Kaufmann H.T.C., Cunha M.D., Benilov M.S., Hartmann W., Wenzel N. // J. Appl. Phys. 2017. V. 122. N 16. P. 163303.

[3] Handbook of vacuum arc science and technology / Eds R.L. Boxman, D.M. Sanders, P.J. Martin. Park Ridge, NJ, USA: Noyes Publications, 1995. P. 138.

[4] Monteiro O.R., Anders A.A. // IEEE Trans. Plasma Sci. 1999. V. 27. N 4. P. $1030-1033$.

[5] Siemroth P., Laux M., Pursch H., Sachtleben J., Balden M., Rohde V., Neu R. // Proc. of the 28th Int. Symp. on discharges and electrical insulation in vacuum (ISDEIV 2018). 2018. V. 1. P. 325-328.

[6] Poluyanova I.N., Zabello K.K., Logatchev A.A., Yakovlev V.V., Shkol'nik S.M. // IEEE Trans. Plasma Sci. 2017. V. 45. N 8. Pt 2. P. 2119-2125.

[7] Логачев А.А., Клочко С.В., Полуянова И.Н. // Письма в ЖТФ. 2017. Т. 43. В. 20. C. 54-60.

[8] Logachev A.A., Poluyanova I.N., Zabello K.K., Begal D.I., Shkol'nik S.M. // Proc. of the 28th Int. Symp. on discharges and electrical insulation in vacuum (ISDEIV 2018). 2018. V. 1. P. 329-332.

[9] Gellert B., Shade E., Dullni E. // IEEE Trans. Plasma Sci. 1987. V. PS-15. N 5. P. 545-551.

[10] Hartmann W., Lawall A., Renz R., Wenzel N., Wietzorek $W$. // Proc. of the 23rd Int. Symp. on discharges and electrical insulation in vacuum (ISDEIV 2008). 2008. V. 1. P. 259-263. 